\title{
1 On-rate modulation of cadherin interactions by chemical fragments
}

3 Akinobu SENOO ${ }^{a}$, Sho ITO ${ }^{\text {b,c }}$, Satoru NAGATOISHI ${ }^{*}$, Yutaro SAITO ${ }^{\mathrm{a}}$, Go UENO ${ }^{\mathrm{e}}$, Kouhei

4 YOSHIDA ${ }^{\mathrm{f}}$, Takumi TASHIMA ${ }^{\mathrm{a}}$, Shota KUDO ${ }^{\mathrm{a}}$, Shinsuke SANDO ${ }^{\mathrm{a}, \mathrm{f}}$, Kouhei TSUMOTO ${ }^{\mathrm{a}, \mathrm{d}, \mathrm{f}^{*}}$

6 a Department of Chemistry and Biotechnology, Graduate School of Engineering, The University of

7 Tokyo, 7-3-1, Hongo, Bunkyo-ku, Tokyo 113-8656, Japan

$8{ }^{b}$ Graduate School of Life Science, University of Hyogo, 3-2-1 Kouto, Kamigori-cho, Ako-gun, Hyogo,

$9 \quad 678-1297$, Japan

$10{ }^{c}$ ROD (Single Crystal Analysis) Group, Application Laboratories, Rigaku Corporation, 3-9-12

11 Matubara-cho, Akishima, Tokyo 196-8666, Japan

$12{ }^{d}$ Institute of Medical Science, The University of Tokyo, 4-6-1, Shirokanedai, Minato-ku, Tokyo 1088639, Japan

${ }^{e}$ RIKEN SPring-8 Center, 1-1-1, Kouto, Sayo-cho, Sayo-gun, Hyogo 679-5148, Japan

${ }^{f}$ Department of Bioengineering, Graduate School of Engineering, The University of Tokyo, 7-3-1,

Hongo, Bunkyo-ku, Tokyo 113-8656, Japan

17 *Corresponding author: Kouhei Tsumoto (tsumoto@bioeng.t.u-tokyo.ac.jp), Satoru Nagatoishi

18 (ngtoishi@ims.u-tokyo.ac.jp) 


\section{Abstract}

2 Many cadherin family proteins are associated with diseases such as cancer. Since cell adhesion

3 requires homodimerization of cadherin molecules, a small-molecule regulator of dimerization would

4 have therapeutic potential. Herein, we describe identification of a P-cadherin-specific chemical

5 fragment that inhibits P-cadherin-mediated cell adhesion. Although the identified molecule is a

6 fragment compound, it binds to a cavity of P-cadherin that has not previously been targeted, indirectly

7 prevents formation of hydrogen bonds necessary for formation of an intermediate called the $\mathrm{X}$ dimer

8 and thus modulates the on-rate of $\mathrm{X}$ dimerization. Our findings will impact on a strategy for kinetic

9 regulation of protein-protein interactions and stepwise assembly of protein complexes using small

10 molecules. 


\section{Introduction}

2 Protein assembly underlies almost all of the biological processes ${ }^{1}$. There has been so much reported

3 structural information on homomers and heteromers in various kinds of functional complexes ${ }^{2}$.

4 Modulators of protein assembly formation have potential as drugs and as probes to investigate protein

5 function. However, the fundamental interaction of the assembly formation; protein-protein interactions

6 are difficult to regulate with small molecules for several reasons: large surface areas are usually

7 involved in interactions between proteins, whereas the accessible surface areas of chemical ligands

8 are small, there are generally no substantial grooves at the protein-protein interface, and there are few

9 natural inhibitors of protein-protein interactions to guide ligand design ${ }^{3-5}$.

11 One of the protein assembly formation can be found in the process of forming cell adhesion by classical cadherin family proteins, calcium-dependent cell adhesive molecules. Depending on biological context, cadherins can play tumor-promoting roles in various tissues ${ }^{6}$. P-cadherin is a classical cadherin family protein. Its overexpression in some cancer tissues has been reported ${ }^{7-11}$, and promotes metastasis and proliferation ${ }^{13-18}$. As formation of cell aggregates blocks anoikis ${ }^{8}$, and Pcadherin-mediated signaling is important for cancer cell survival ${ }^{17}$, inhibition of P-cadherin function

17 is a potential anticancer strategy. Cell adhesion is achieved through trans homodimerization between cadherins on apposed cells and then cis clustering of cadherins on the same cell surface ${ }^{18}$ (Fig. 1a). 
1 For some type I classical cadherins, including P-cadherin, trans homodimerization has been

2 intensively studied, and the two extracellular domains of five on the protein that interact during the

3 step-wise process have been identified ${ }^{19-22}$ (Fig. 1a). The $\mathrm{X}$ dimer is an intermediate state that

4 favorably promotes the final dimerized state, which is called the strand-swap dimer (S-S dimer). The

5 S-S dimer has a unique binding mode in which a tryptophan residue of the $\mathrm{N}$ terminal strand of one

6 monomer is swapped into a hydrophobic pocket of the other monomer. Based on this binding mode,

7 several peptide mimetic ligands have been reported ${ }^{23-28}$; however, no ligands that bind to the

8 hydrophobic pocket have been identified, and the molecular basis of inhibition of homodimerization

9 by these peptide mimetics has not been elucidated. Orthosteric inhibition of S-S dimerization, which

10 is the last stage in the assembly process, may not be the best way to regulate the process. We have to

11 change direction to find other way to effectively regulate the cell adhesive assembly with a small molecule.

In this study, we performed screen for inhibitors at any stage of the process. We screened a library that

17 the on-rate of $\mathrm{X}$ dimerization, indirectly blocking formation of hydrogen bonds that stabilize the $\mathrm{X}$ 


\section{$1 \quad$ Results}

\section{SPR-based fragment screen.}

3 SPR-based fragment screen was performed as described previously ${ }^{29}$ (Fig. 1b). The fragment library

4 was ordered from Drug Discovery Initiative; it contained 1973 compounds. As a primary screen, a

5 direct binding assay was performed. Monomer mutant of P-cadherin called REC12 ${ }^{21}$ was immobilized

6 on the Sensor Chip SA via biotin-streptavidin capture method and $100 \mu \mathrm{M}$ of each compound was

7 injected onto the sensor chip surface. Based on immobilization level and molecular weights of REC12

8 and fragment compounds, we estimated that the $\mathrm{R}_{\mathrm{MAX}}$ value of the binding response would be around

$920 \mathrm{RU}$. Of the 1973 compounds in the library, 144 compounds had binding responses greater than 10

10 RU (Supplementary Fig. S1a).

12 As a secondary screen, we immobilized a construct called EC12 on the Sensor Chip CM5.This

construct is in equilibrium between monomer and S-S dimer. We performed the so-called ABA assay,

in which two solutions, A and B, are injected successively. In our experiments, $2 \mu \mathrm{M}$ EC12 was used

as a solution $\mathrm{A}$, and $100 \mu \mathrm{M}$ of each of the compounds identified in the primary screen was used as a

solution B. In both A parts, the binding responses of monomer in the analyte and monomer covalently

17 linked to the sensor chip surface were obtained. Two compounds significantly decreased the response 
1 dimerization such that monomers that were not covalently immobilized on the sensor chip dissociated

2 from the chip surface. Only one of the two compounds, Hit 1 here after, showed a dose-response

3 dependency in the direct binding assay (Fig. 1d). The approximate $K_{D}$ value of Hit 1 (Fig. 1e) for the

4 monomer mutant was calculated to be $916 \mu \mathrm{M}$.

5 
a
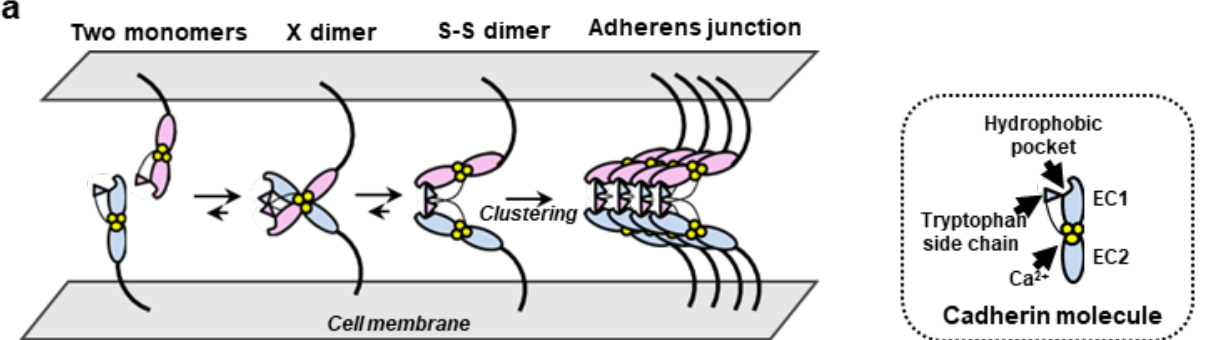

b

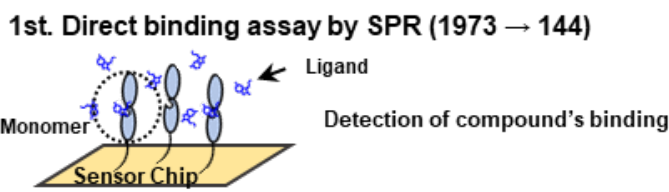

2nd. ABA assay by SPR $(144 \rightarrow 2)$
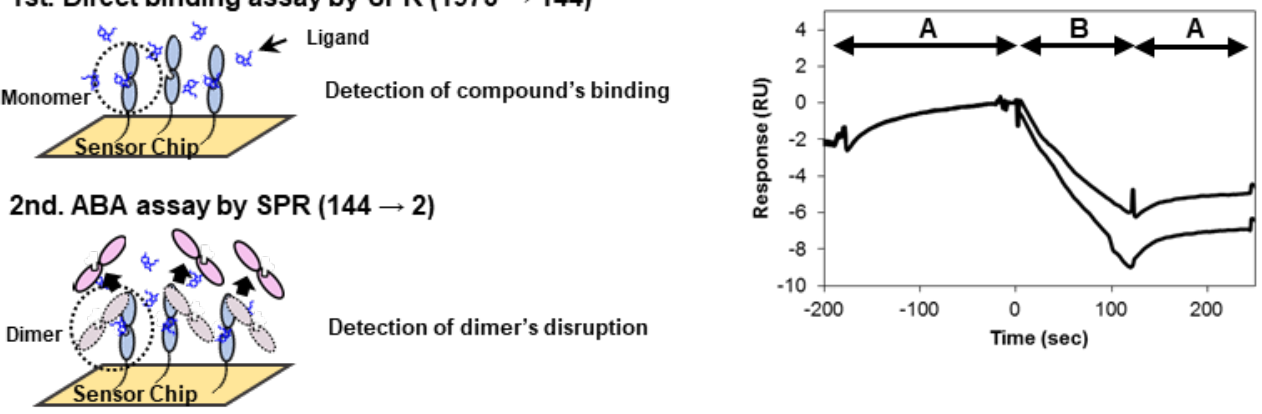

3rd. Direct binding dose dependency check $(2 \rightarrow 1)$

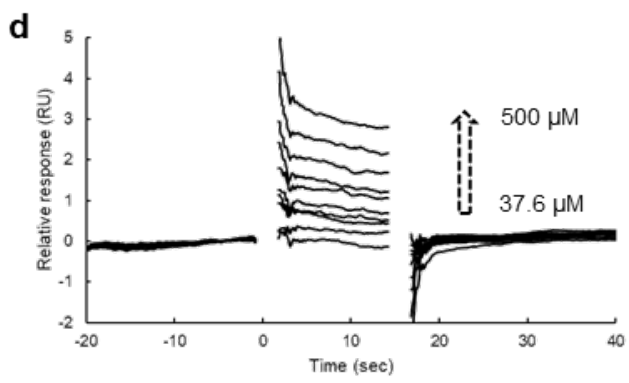

e<smiles>Cc1[nH]c2ccc(Cl)cc2c1CCN</smiles>

Hit 1

Hit 1: $K_{D}=916 \mu \mathrm{M}$

2 Fig. 1 | SPR-based fragment screening. (a) Illustration of the stepwise dimerization of P-cadherin to

3 mediate cell adhesion and a schematic of the protein (EC12). (b) Schematic of fragment screening. (c)

4 Representative sensorgram from ABA assay with EC12, in monomer-S-S dimer equilibrium, was

5 immobilized on Sensor Chip CM5. The decrease of response upon injection of solution B shows that

6 the compound disrupted the dimer formed on the sensor chip. (d) Dose-response analysis of binding

7 of Hit 1 to REC12 immobilized on Sensor Chip SA. The putative $K_{D}$ was calculated by the Scatchard 

made available under aCC-BY-NC-ND 4.0 International license.

1 method using the SPR responses in equilibrium. Note that the $K_{\mathrm{D}}$ value is not reliable, since the binding

2 response was not saturated even at the highest concentration of Hit 1. (e) Chemical structure of Hit 1. 
1 Identification of a ligand binding site for Hit 1.

2 We employed X-ray crystallography to identify the binding site of Hit 1 to REC12 and to elucidate the

3 inhibitory mechanism of Hit 1 . REC12 was crystallized and soaked with Hit 1 at $10 \mathrm{mM}$ final

4 concentration. The resulting complex diffracted to $2.30 \AA$ resolution (Fig. 2a, Supplementary Table 1 ,

5 Supplementary Fig. S2). Electron density corresponding to Hit 1 was observed inside a shallow cavity

6 located between the EC1 and EC2 domains. Upon binding of Hit 1, the side chain of Y140 shifted

7 relative to its position in the crystal structure of REC12 alone (PDB ID; 4zmz) (Fig. 2b), and Y140

8 and Hit 1 form a $\mathrm{CH}-\pi$ interaction. A water molecule was located in the cavity in the crystal structure

9 of REC12 alone (PDB ID; 4zmz). Thus, the driving forces that result in of Hit 1 binding appear to be

10 the interaction with Y140 residue, and the dehydration. Hit 1 also has some van der Waals interactions

11 with R68, V98, T99, D100, and D137 (Fig.2c). In order to confirm the binding mode observed in the

crystal structure, we performed a SPR-based direct binding assay using REC12 Y140R mutant. Hit 1

did not bind to this mutant (Supplementary Fig. S3), validating the contribution of Y140 to the binding

observed in the crystal structure. Several residues around this binding pocket are reported to be 
2 Interestingly, when we superposed the P-cadherin-Hit 1 complex structure with that of E-cadherin

3 (PDB; 2072), we found that the volume of the cavity in E-cadherin was smaller than that in P-cadherin

4 (Fig. 2d). Indeed, volumes of the cavities in the P-cadherin apo structure (PDB ID; 4zmz), the E-

5 cadherin structure (PDB ID; 2o72), and the P-cadherin monomer-Hit 1 complex structure calculated

6 using CASTp ${ }^{30}$ were $12.173 \AA^{3}, 5.441 \AA^{3}, 21.427 \AA^{3}$, respectively, suggesting that P-cadherin but not

7 E-cadherin, has a suitable cavity for the binding of Hit 1. Moreover, FTMap analysis ${ }^{31}$ regarded the

8 region as a binding cavity only in the P-cadherin structure, not in E-cadherin structure (Supplementary

9 Fig. S4). As expected, Hit 1 did not bind to E-cadherin but did bind to the E-cadherin N140Y mutant

10 in the SPR-based direct binding assay (Fig. 2e). The N140Y point mutation did not affect the secondary

11 structure of the recombinant E-cadherin, as confirmed using circular dichroism spectroscopy

12 (Supplementary Fig. S5). Therefore, the binding cavity of Hit 1 could be used as a starting point for 

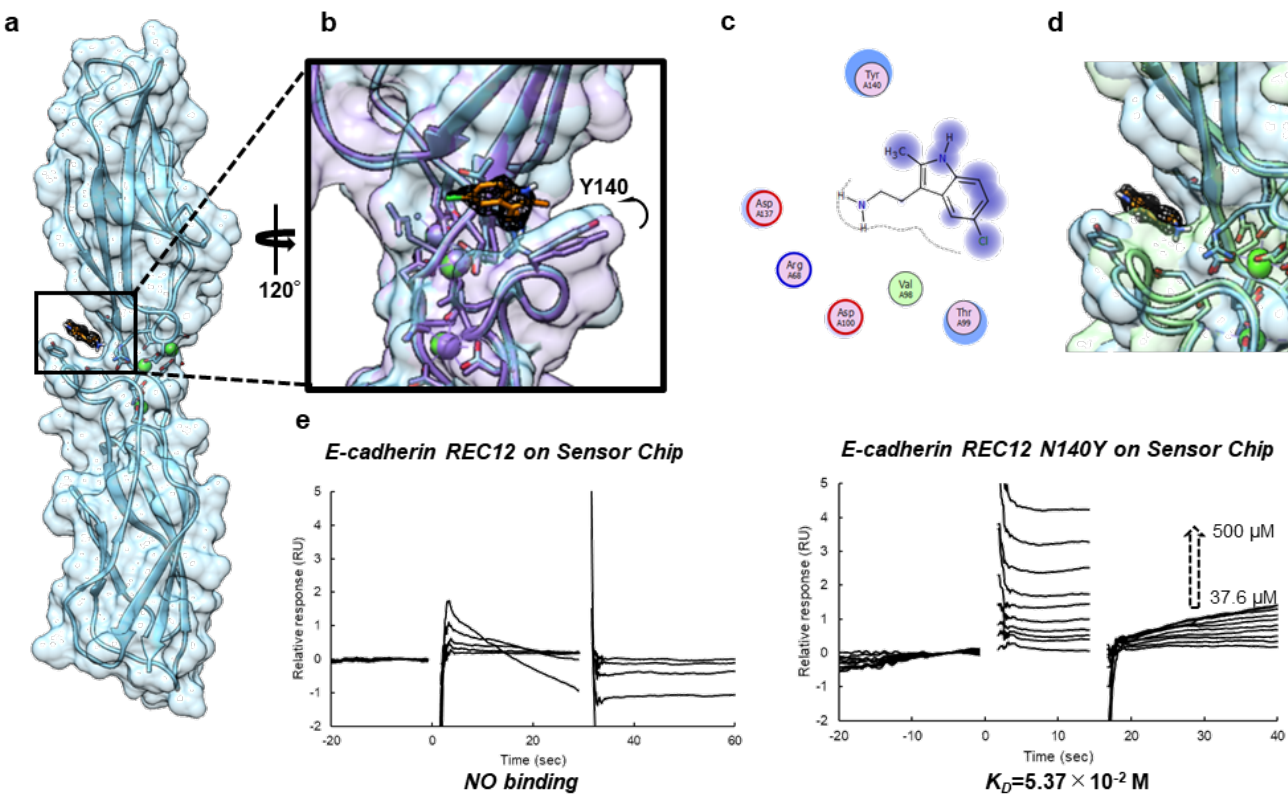

1 Fig. 2 | Hit 1 binds selectively to P-cadherin. (a) Structure of complex of REC12 with Hit 1 . Hit 1 is

2 colored orange. (b) Region of the Hit 1-binding cavity, illustrating the shift in the side chain of Y140

3 that occurs upon compound binding. $2 \mathrm{mFo}-\mathrm{DFc}$ map at $1.0 \sigma$ level is shown. The $\mathrm{P}$-cadherin monomer

4 (PDB ID; 4zmz) is superposed (purple). (c) 2D interaction map of Hit 1 made with FLEV ${ }^{32}$. The

5 reduction of solvent exposure upon Hit 1 binding is indicated by the halo-like disc around the residues.

6 (d) Superposition of P-cadherin REC12-Hit 1 complex and E-cadherin structure (PDB ID 2o72; green).

7 (e) Sensorgram from SPR-based binding assay of WT E-cadherin and E-cadherin N140Y with Hit 1.

8 This experiment was repeated at least twice, and similar results were obtained. 


\section{Effect of Hit 1 on $\mathbf{X}$ dimerization.}

2 To monitor the effect of Hit 1 on $\mathrm{X}$ dimerization, we used hydrogen-deuterium exchange mass

3 spectrometry (HDX-MS). The method allowed us to monitor the extent to which the interface of X

4 dimer is exposed to the solvent in the presence or in the absence of Hit 1. Pepsin treatment before LC-

5 MS yielded peptide fragments from almost all regions of the P-cadherin molecule (Supplementary Fig.

6 S6a, S6b. S6c). The HDX ratios for each peptide with and without Hit 1 were determined

7 (Supplementary Fig. S6d and Fig. S6e). In the region that corresponds to one of the interfaces (residues

8 134-140 and 137-147) of MEC12, a construct that forms the X dimer but not the S-S dimer, the HDX

9 ratio in the presence of Hit 1 was higher than in the absence of Hit 1, although not as high as that of

10 REC12 (Fig. 3a). This result suggests that the equilibrium between monomer and X dimer shifted

11 toward the monomer form in the presence of Hit 1 . The assay does not reflect all the residues at the

interface between monomers in the X dimer (Supplementary Fig. S6f, Fig. S6g). This may be because

the interface of the $\mathrm{N}$ terminal region involved in the interaction of the $\mathrm{X}$ dimer is too dynamic to

analyze in HDX-MS, since the HDX reaction occurs in regions exposed to the solvent due to dynamics.

16 To further investigate how Hit 1 affects X dimerization, MEC12 was crystallized and soaked with Hit

171 at $10 \mathrm{mM}$ final concentration, resulting in the complex structure at $2.45 \AA$ resolution (Fig. $3 \mathrm{~b}$,

18 Supplementary Table 1). Three independent sets of electron density that can be modeled as Hit 1 were 
1 found, two of them in the cavity around Y140, the other at the intersection of EC2 domains (Fig. 3b).

2 The Hit 1 molecules bound in the cavity formed $\pi-\pi$ interaction with Y140 and hydrogen bonds with

3 residues or water molecules around the pocket (Supplementary Fig.S7). The Hit 1 molecule at the

4 intersection of EC2 domains bound mainly due to van der Waals interaction (Supplementary Fig. S7).

5 The cavity around Y140 has a different structure through X dimerization from monomer and the

6 binding mode of Hit 1 likely differs to fit the cavity.

8 A drastic structural change was observed in Hit 1-bound X dimer when compared with the apo form

9 of X dimer (PDB ID; 4zmq). The angle of EC1-EC2 domain became flatter and chain B was shifted

relative to chain A (Fig. 3c). This structural change in angle can be explained most reasonably by two

11 Hit 1 molecules bound in the cavity around Y140. Hydrogen bonds including one between the side

chain of K14 and the main chain of A138' at the interface of X dimer were disrupted upon Hit 1 binding

13 (Figure 3d), which could explain the shifted location of two monomers. The Hit 1-bound X dimer seems to be in a metastable state; therefore the Hit 1 interaction may affect the dissociation of the $\mathrm{X}$

dimer.

17 To confirm that the hydrogen bond between the side chain of K14 and the main chain of A138' is

18 important for $\mathrm{X}$ dimerization as previously reported ${ }^{21}$, we used a size exclusion chromatography- 
1 multiangle light scattering (SEC-MALS) analysis. Indeed, the K14A mutant was mainly in monomer

2 form (Fig.3e). Together, these data suggest that Hit 1 binding interferes with formation of hydrogen

3 bonds necessary for $\mathrm{X}$ dimerization. Unlike a typical orthosteric inhibitor, Hit 1 did not directly block

4 hydrogen bonding between two monomer units; rather, Hit 1 alters the monomer structure to prevent

5 hydrogen bond formation. 


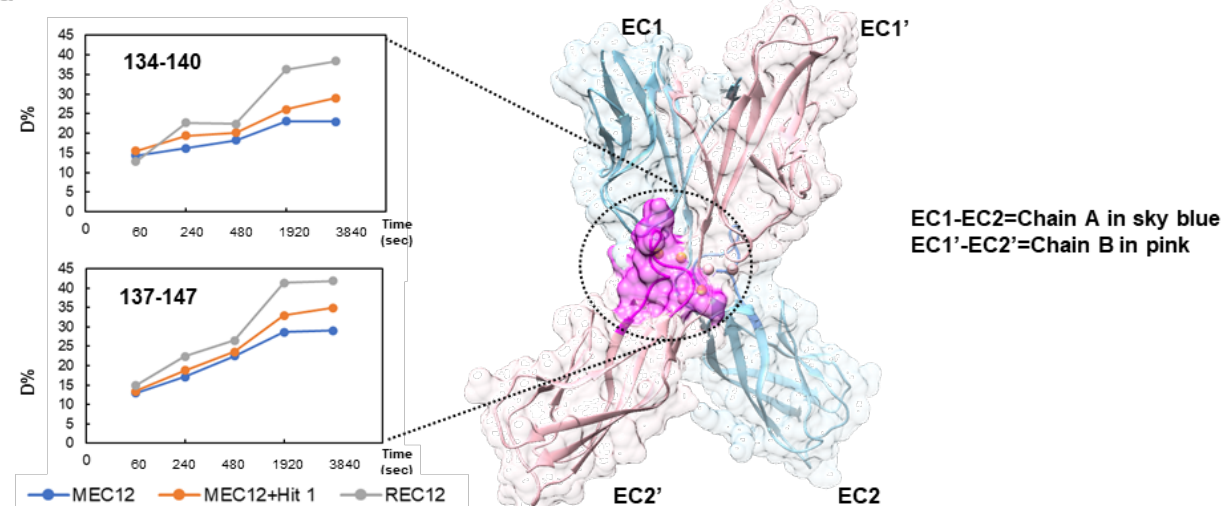

b

EC1

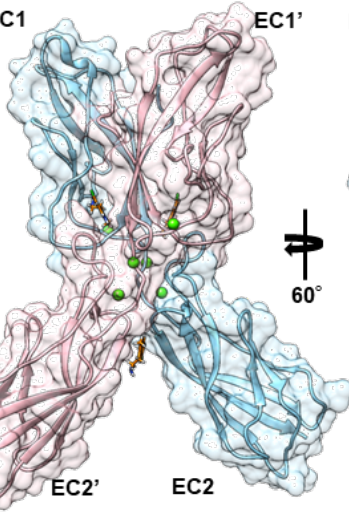

d

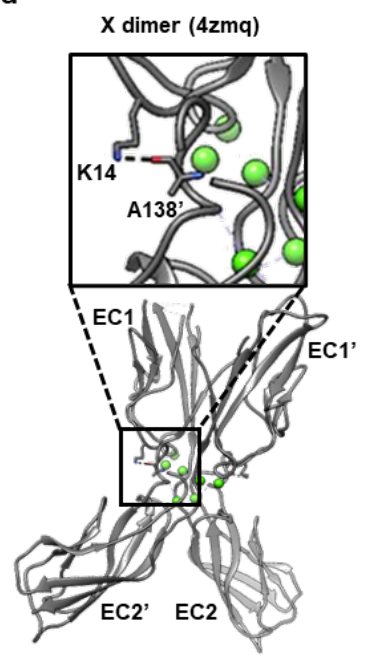

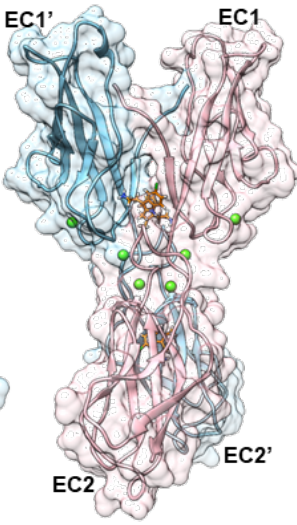

EC1
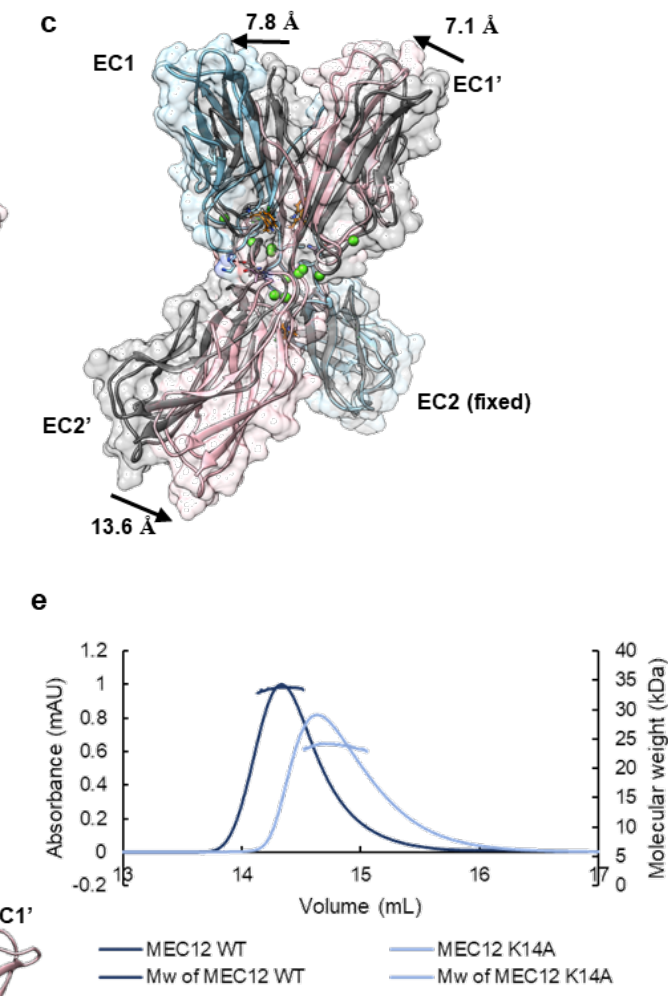

-Mw of MEC12 WT $\quad$ Mw of MEC12 K14A

1 Fig. 3 | Effects on X dimerization by Hit 1. (a) Hydrogen-deuterium exchange ratio of two peptides

$2 \quad 134-140$ and $137-147$ as a function of time. The region of these peptides is colored in magenta in the

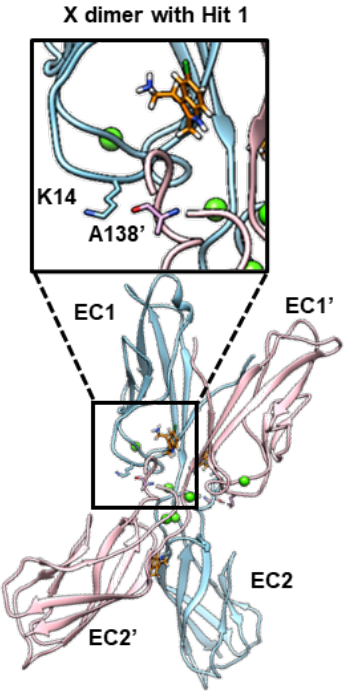

structure of MEC12, X dimer (PDB ID; 4zmq). Chain A of X dimer is colored in sky blue; chain B in 
1 pink. (b) Structure of the complex of the X dimer and Hit 1. Hit 1 (orange) is bound in the cavity

2 around Y140 and at the intersection of EC2 domains. (c) Structural change caused by the binding of

3 Hit 1 . The angle of EC1 to EC2 is flatter compared to that in the apo X dimer (PDB ID; 4zmq, grey).

4 The arrows indicate movement of domains. (d) Hydrogen bonds disrupted by the structural change

5 that occurs upon Hit 1 binding. Left: Apo X dimer with K14-A138' hydrogen bond is shown in dotted

6 line. Right: Hit 1-bound X dimer; the K14-A138' hydrogen bond is disrupted. Amino acid residues

7 from chain A are shown in sky blue, those from chain B are in pink. (e) Size measurement using SEC-

8 MALS. The WT X dimer trace is in dark blue, the K14A mutant trace is in light blue. 


\section{$1 \quad$ Inhibition of cell adhesion by Hit 1.}

2 We next investigated whether or not Hit 1 could inhibit cell adhesion, using a previously established

3 cell aggregation assay ${ }^{33,34}$. We established a $\mathrm{CHO}$ cell line expressing P-cadherin using the Flp-In-

4 CHO system. In this assay, extracellular proteins other than P-cadherin are trypsinized so that cell

5 adhesion and formation of cell aggregates depend only on the interaction of P-cadherin molecules.

6 After the trypsinization, the culture medium was replaced with medium without calcium so that the

7 cells were not aggregated. The aggregation reaction was initiated by addition of $1 \mathrm{mM} \mathrm{CaCl}$. As

8 control experiments, 1 mM EDTA was added (Fig. 4a). EDTA inhibited formation of cell aggregates;

9 thus adhesion is based on the calcium-dependent interaction of P-cadherin molecules. When Hit 1 and

$101 \mathrm{mM} \mathrm{CaCl}_{2}$ were added simultaneously, aggregation was inhibited in a manner that depended on the

11 Hit 1 concentration (Fig. 4b). When Hit 1 was added to pre-formed cell aggregates, the aggregates remained stable in the time scale of this assay; EDTA did disrupt pre-formed aggregates state at the cellular level. We hypothesize that Hit 1 blocks association of two monomers by affecting the on-rate of $\mathrm{X}$ dimerization.

17 To quantify the effect of Hit 1 on the on-rate of $\mathrm{X}$ dimerization, we performed a liposome aggregation 
1 based liposome that contained 10\% Ni-chelating lipid DOGs-NTA-Ni in the presence of EDTA to

2 deactivate P-cadherin molecules. Under these conditions, no aggregation was observed as monitored

3 by absorbance at $650 \mathrm{~nm}$ (Fig. 4c). We also confirmed that liposome aggregation only happens in the

4 presence of both $\mathrm{MEC12}$ and $\mathrm{CaCl}_{2}$ (Fig. 4c). Upon addition of $\mathrm{CaCl}_{2}$ to the solution, liposomes

5 aggregated, presumably through $\mathrm{X}$ dimerization of $\mathrm{C}$ terminally His-tagged MEC12 molecules

6 captured on the surface of the liposomes as indicated by a gradual increase in absorbance at $650 \mathrm{~nm}$

7 that reached a plateau (Fig. $4 \mathrm{c})$. The observed rate constant $\left(k_{o b s}\right)$ of the liposome aggregation was

8 calculated as an indicator of the on-rate of $\mathrm{X}$ dimerization using an exponential decay equation model

9 of the one-phase association. The $k_{o b s}$ value was considerably lower in the presence of Hit 1 than in

10 the absence of Hit 1 (Fig. 4d, Supplementary Fig. S9). This result supports our hypothesis that Hit 1

11 inhibits $\mathrm{X}$ dimerization and presumably cell aggregation, through on-rate modulation caused by the indirect disruption of hydrogen bonds necessary for $\mathrm{X}$ dimerization.

We also analyzed the effects of Hit 1 on cell adhesion mediated by endogenous P-cadherin and on

cells that do not express P-cadherin using two cancer cell lines; HCT116 cells express P-cadherin ${ }^{17}$,

16 and MCF7 cells do not ${ }^{35}$. Cells were plated in the presence of $100 \mu \mathrm{M}$ Hit 1 and cell adhesion was

17 quantified by cell area. The normalized cell area of HCT116 cells was significantly decreased in the

18 presence of Hit 1 compared to its absence, but Hit 1 had no effect on normalized MCF7 cell area (Fig. 

made available under aCC-BY-NC-ND 4.0 International license.

14 4). This result indicates that Hit 1 blocks adhesion of cancer cells that express P-cadherin. 
a

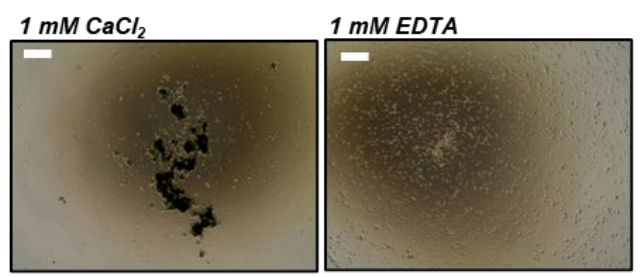

b

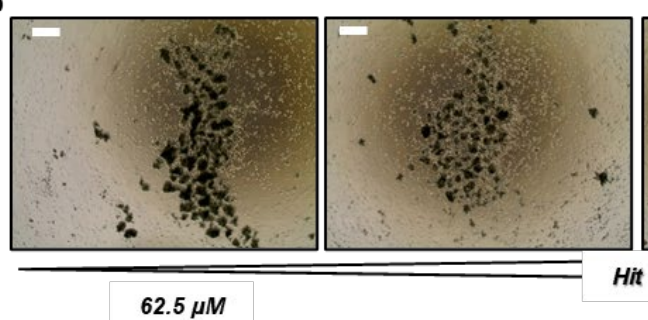

C

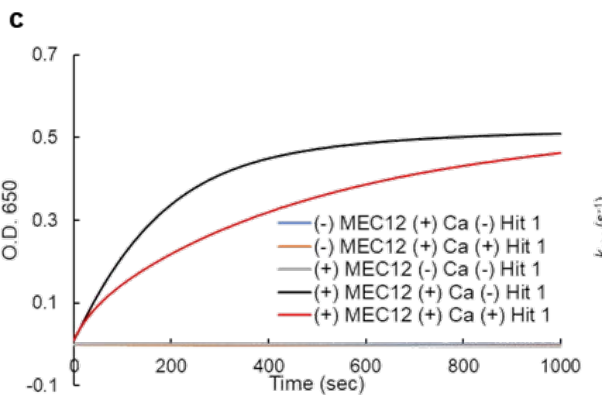

d

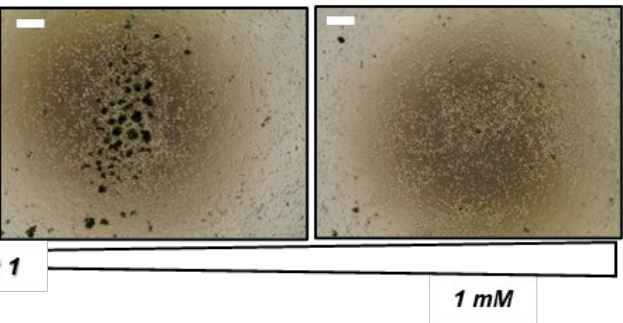

e
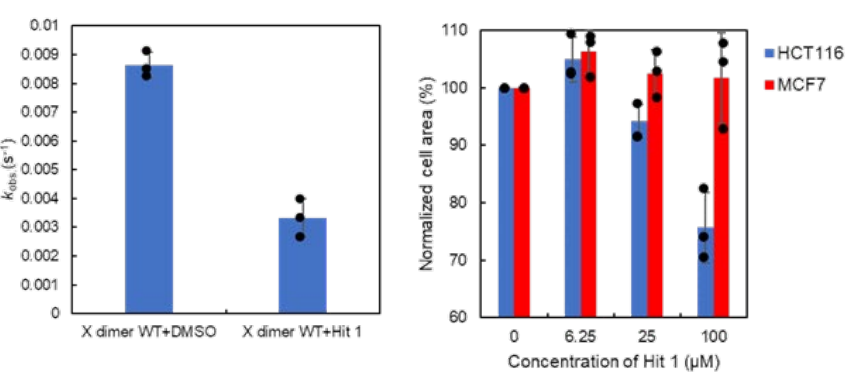

$2 \quad$ Fig. 4 | Hit 1 blocks aggregation of liposomes and cells with P-cadherin on their surfaces. (a)

3 Images of $\mathrm{CHO}$ cell line expressing P-cadherin in the presence of $1 \mathrm{mM} \mathrm{CaCl}_{2}$ (left) and $1 \mathrm{mM}$ EDTA

4 (right). Scale bars indicate $500 \mu \mathrm{m}$. (b) Representative images of CHO cell line expressing P-cadherin

5 in the presence of $1 \mathrm{mM} \mathrm{CaCl}_{2}$ and increasing concentrations of Hit 1 . This experiment was repeated

6 at least three times, and similar results were obtained. Scale bars indicate $500 \mu \mathrm{m}$. (c) Liposomes with

7 MEC12 on the surface were incubated with $\mathrm{CaCl}_{2}$ and with (red) or without (black) Hit 1. Controls

8 had no effect on optical density (blue, yellow, and grey traces). Optical density at $650 \mathrm{~nm}$ was 
1 monitored as a function of time. (d) The $k_{\text {obs }}$ of liposome aggregation calculated assuming a one-phase

2 association model. $\mathrm{N}=3$. Error bars show standard deviation. Individual data points are shown in black

3 plots. (e) Normalized area of HCT116 and MCF7 cells in the presence or absence Hit 1. In order to

4 take cell shape into account, the cell area in the absence of Hit 1 was taken as $100 \%$. N=3. Error bars

5 show standard deviation. Individual data points are shown in black plots. 


\section{Design of a more potential inhibitor.}

2 Since Hit 1 and many of the compounds identified in the primary screen had cationic functional groups,

3 we firstly checked whether the cationic functional group is important for binding activity by testing

4 commercially available indole-based compounds: tryptamine, tryptophan, and auxin (Fig. 5a).

5 Surprisingly, only tryptamine bound to P-cadherin (Supplementary Fig. S10a), which may be because

6 the protein surface around the cavity where Hit 1 binds is negatively charged (Supplementary Fig.

7 S10b). This result indicated that the cationic functional group should not be modified during further

8 development.

10 Upon study of the 2D interaction map of Hit 1 with the P-cadherin monomer (Fig. 2c), we came up

11 with two strategies for the further synthesis: 1) replacement of the methyl group at the second position

of the indole ring with a carboxy group, which should result in formation of salt bridges between the

13 carboxy group with R68 and the amino group with D137 and 2) replacement of the chlorine group at

the $\mathrm{C} 5$ position of the indole ring with a bulkier functional group to inhibit approach of the second

monomer. We first synthesized 3-(2-aminoethyl)-5-phenyl-1H-indole-2-carboxylic acid (Hit 1- 
2 Next, we synthesized 2-(2-methyl-5-phenyl-1H-indole-3-yl)ethan-1-amine (phenyl-Hit 1) (Fig. 5b).

3 In the SPR-based direct binding assay, we observed a dose-dependent response; the binding affinity

4 for REC12 was equivalent to that of Hit 1 (Supplementary Fig. S12). In the liposome aggregation

5 assay, phenyl-Hit 1 had stronger inhibitory activity than Hit 1; tryptamine auxin, and tryptophan had

6 little effect on aggregation (Fig. 5c, Supplementary Fig. S9). Tryptamine does not have a bulky

7 functional group, which is likely why it did not inhibit liposome aggregation. In the cell aggregation

8 assay, phenyl-Hit 1 inhibited cell aggregation much more strongly than did Hit 1 (Fig. 5d), whereas

9 negative controls and tryptamine did not (Supplementary Fig. S13). Given this strong inhibitory

10 activity, the binding affinity of Phenyl-Hit 1 to $\mathrm{X}$ dimer could be stronger than to monomeric $\mathrm{P}$ -

11 cadherin. 
a

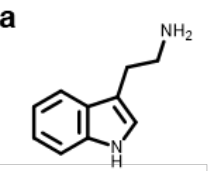

Tryptamine

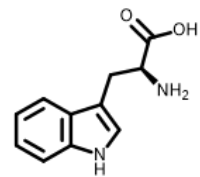

L-Tryptophan

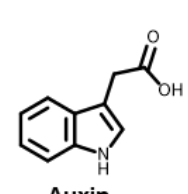

Auxin

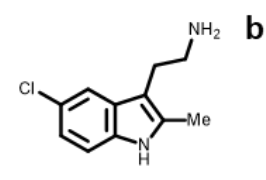

Hit 1

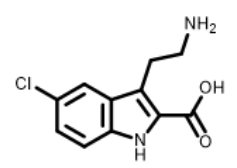

Hit 1-carboxylic acid

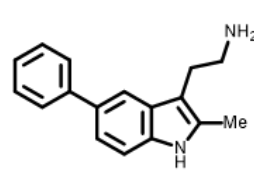

Phenyl-Hit 1

c

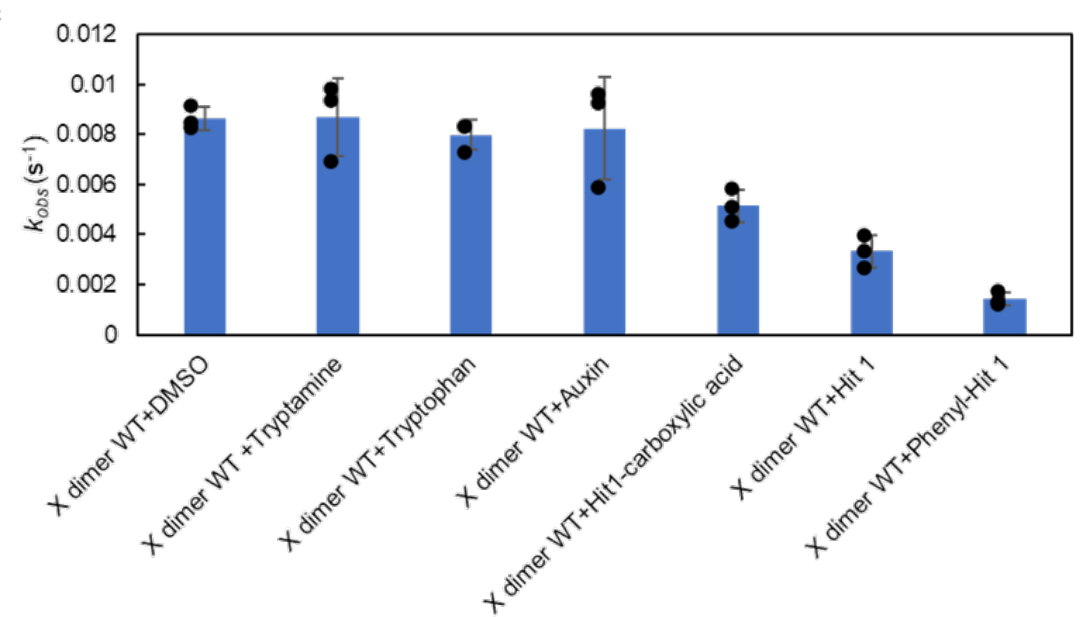

d

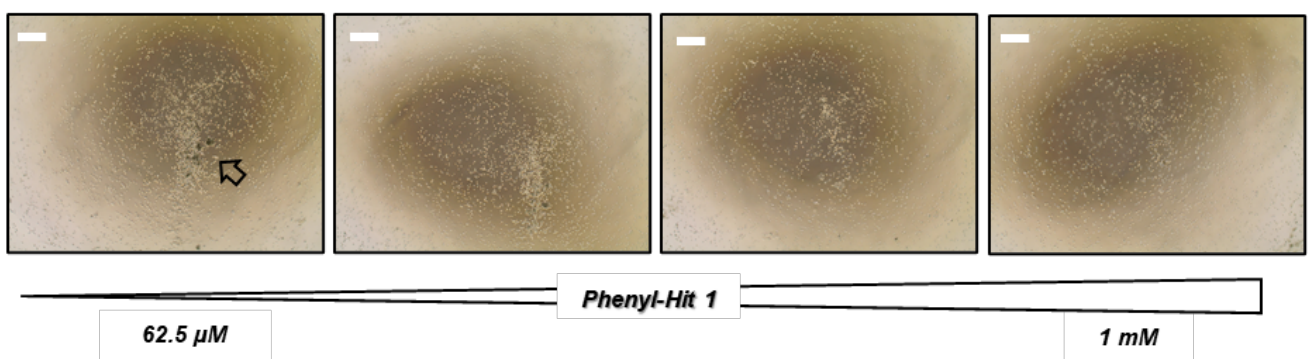

2 Fig. 5 | Phenyl-Hit 1 more effectively inhibits aggregation than does Hit 1. (a), (b) Chemical

3 structures of the compounds investigated. (c) The $k_{\mathrm{obs}}$ values for indicated compounds in the liposome

4 aggregation assay $\mathrm{N}=3$. Error bars show standard deviations. Individual data points are shown in black

5 plots. (d) Representative images from cell aggregation assay in the presence of a range of

6 concentrations of phenyl-Hit 1. Scale bars indicate $500 \mu \mathrm{m}$. Black arrow indicated small aggregates 

made available under aCC-BY-NC-ND 4.0 International license.

1 formed in the presence of the lowest concentration. This experiment is repeated at least twice, and

2 similar results were obtained.

3 


\section{Discussion}

2 Through biophysical and structural methods, we identified a class of fragment compounds that bind

3 to a unique shallow cavity on P-cadherin between the EC1 and EC2 domains. Our chemical fragment

4 has a potential to modulate $\mathrm{X}$ dimer through the effect of on-rate modulation, by altering the angle of

5 the EC2 domain relative to the EC1 domain, blocking formation of key hydrogen bonds necessary for

$6 \mathrm{X}$ dimerization (Fig. 3c, Fig. 6). This is the first report of an inhibitor of a classical cadherin family

7 protein that has a mechanism other than an orthosteric one. Now our fragments had an impact on

8 kinetics; probably because the energy barrier to remove the bound ligand should be cleared to complete

9 the X dimerization. SPR-based compound screen can provide an ideal platform to select such a kinetic

10 modulator, since a flow system of SPR itself could help the inhibition of interaction, and thus the

11 inhibitory mechanism should not be so strong as to be a thermodynamic one. We propose that on-rate

modulation utilizing the restricted protein domain angle provides a common strategy to regulate PPI

of cell adhesive molecule with a small molecule, since not only cadherin superfamily proteins but also

integrin superfamily proteins and immunoglobulin superfamily proteins have multi-domain structures

and similar cavities located between the domains could be targeted to regulate the protein dynamics

necessary for function. 
1 dimerization, indicated that thermodynamic inhibition of $\mathrm{X}$ dimer leads to inhibition of S-S

2 dimerization, and thus cell adhesion ${ }^{36}$. Hit 1 modulated the on-rate of $\mathrm{X}$ dimerization, and despite the

3 lack of a strong thermodynamic effect, inhibited cell adhesion. This result implies that every step-wise

4 process like formation of cell adhesion assembly has a check point, such as the intermediate like $\mathrm{X}$

5 dimer state, that decreases the energy barrier to the final state and that a slight, kinetic-level inhibition

6 of the key step can lead to significant inhibition of formation of the final state. The most effective

7 small-molecule inhibitor of the formation of a macromolecule complex should block the initial

8 association of the component proteins. In other words, it is this initial association of the component

9 molecules that should be targeted for the drug discovery of the field.

11 From our simple structure-activity relationship study, we determined that an inhibitor with specificity

12 for P-cadherin requires 1) a cationic functional group to interact with the negatively charged region

13 around the cavity located between the $\mathrm{EC} 1$ and $\mathrm{EC} 2$ domains, 2) functional groups that interact with

14 Y140, a unique residue to P-cadherin, and 3) a bulky functional group that protrudes from the interface

15 to block X dimerization. Our structure-activity relationship also suggests that strong affinity for the

protein-protein interface itself is not strictly necessary for inhibition of protein complex formation

17 since it is not the equilibrium but rather the first contact of component molecules that an inhibitor

18 should affect. 
2 We discovered that tryptamine but not tryptophan binds to P-cadherin. It is known that several

3 tryptamine-derived metabolites have their own biological role ${ }^{37,38}$. One tryptamine derivatives,

4 serotonin, is important in the function of digestive organs including gastric tissue ${ }^{39}$; P-cadherin is

5 overexpressed in gastric cancer. It is possible that tryptamine derivatives, through weak interactions

6 with P-cadherin, subtly regulate cell adhesion. In support of this hypothesis, relationships between

7 serotonin activity and cell adhesion phenotypes have been demonstrated ${ }^{40-42}$.

9 In summary, the chemical fragment we identified acts through an on-rate modulation mechanism to

10 inhibit formation of an intermediate in dimerization of P-cadherin. Cadherin family proteins, including

11 P-cadherin, are associated with diseases such as cancer; thus, the small-molecule regulator of dimerization we identified has therapeutic potential. Further, our strategy for kinetic regulation of protein-protein interactions and stepwise assembly of protein complexes using small molecules could be applied to identify inhibitors of formation of other macromolecular complexes. 
1
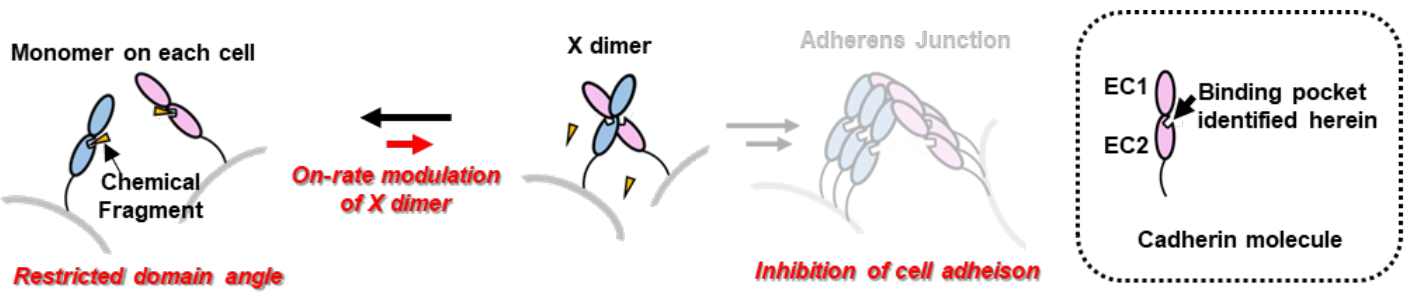

2 Fig. 6 | On-rate modulation mechanism of inhibition of cell adhesion by a chemical fragment. In

3 the presence of chemical fragments, the angle between the EC1 and EC2 domains is not optimal for

$4 \mathrm{X}$ dimerization; thus, the association of two monomers to form $\mathrm{X}$ dimer becomes slower. This kinetic

5 effect can be strong enough to inhibit cell adhesion.

6 


\section{$1 \quad$ Methods}

2 Protein expression and purification. For the in vitro assays including SPR-based screen, crystallography, HDX-MS, and SPR-based selectivity analysis, human P-cadherin constructs and

4 human E-cadherin constructs were expressed in E. coli Rosetta2(DE3). E. coli cells were transformed

5 with the pET SUMO vector and used to inoculate $6 \mathrm{~mL} \mathrm{LB}$ medium containing $50 \mathrm{mg} / \mathrm{mL}$ kanamycin

6 and $34 \mathrm{mg} / \mathrm{mL}$ chloramphenicol. Cells were pre-cultured at $37^{\circ} \mathrm{C}$ for $16 \mathrm{~h}$ then transferred into $1 \mathrm{~L}$ of

7 fresh LB medium containing the same antibiotics and cultured again at $37^{\circ} \mathrm{C}$ for $4 \mathrm{~h}$. At this time, the

8 O.D.600 was around 0.5. Isopropyl $\beta$-D-1-thiogalactopyranoside (IPTG) was added to $0.5 \mathrm{mM}$ to

9 induce recombinant protein expression. After $16 \mathrm{~h}$ at $20^{\circ} \mathrm{C}, E$. coli cells were collected by centrifugation at $7000 \mathrm{~g}$ at $4{ }^{\circ} \mathrm{C}$ for $10 \mathrm{~min}$, suspended in binding buffer $(20 \mathrm{mM}$ Tris, $300 \mathrm{mM} \mathrm{NaCl}$,

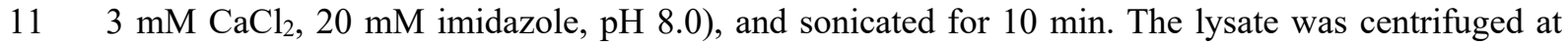
$40000 \mathrm{~g}, 4{ }^{\circ} \mathrm{C}$, for $30 \mathrm{~min}$. The supernatant was purified on a Ni-NTA agarose (QIAGEN) column, pre-equilibrated with the binding buffer. The His-tagged protein was eluted with elution buffer (20

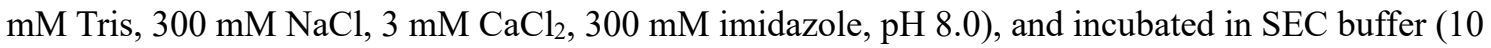
mM HEPES, $150 \mathrm{mM} \mathrm{NaCl}, 3 \mathrm{mM} \mathrm{CaCl}_{2}, \mathrm{pH}$ 7.5) with Ulp1 protease to remove the SUMO protein.

17 further purified with size-exclusion chromatography (SEC). The protein was loaded onto a Hiload 
1 based on EC12 (1-241), which consists of two extracellular domains. For the control experiments in

2 SPR-based direct binding screen, anti-P-cadherin scFv TSP7 was prepared. The expression host was

3 E. coli BL21 (DE3). Binding buffer contained $20 \mathrm{mM}$ Tris, $500 \mathrm{mM} \mathrm{NaCl}, 5 \mathrm{mM}$ imidazole, $\mathrm{pH}$ 8.0.

4 The elution buffer was $20 \mathrm{mM}$ Tris, $500 \mathrm{mM} \mathrm{NaCl}, 300 \mathrm{mM}$ imidazole, $\mathrm{pH}$ 8.0. In SEC process, a

5 Hiload 26/60 Superdex-75 column (Cytiva) was used in $20 \mathrm{mM}$ Tris, $200 \mathrm{mM} \mathrm{NaCl}$, pH 8.0 buffer.

7 Compounds. The fragment library used in the SPR-based screen was purchased from Drug Discovery

8 Initiative. Hit 1 was purchased from Vitas-M Laboratory. For HDX-MS experiments, SPR-based

9 selectivity analysis, and the mutation study, Hit 1 was synthesized in house. The synthetic scheme,

10 procedures, and compound characterization are described in supplementary materials. Tryptamine,

11 auxin, and L-tryptophan were purchased from Sigma Aldrich or Nacalai Tesque. Stock solution of all the compounds were prepared in DMSO and stored at $-30{ }^{\circ} \mathrm{C}$.

15 Direct binding analysis using SPR. For the primary screen, we performed a direct binding assay

17 Monomer construct of REC12 was immobilized on the Sensor Chip SA via biotin-streptavidin capture.

18 The immobilization level was approximately 3000 RU. Fragment compounds were injected onto the 
1 sensor chip surface in running buffer (10 mM HEPES, $150 \mathrm{mM} \mathrm{NaCl}, 3 \mathrm{mM} \mathrm{CaCl} 2,0.05 \%$ Tween20,

$25 \%$ DMSO, $\mathrm{pH} 7.5$ ) to a final concentration of $100 \mu \mathrm{M}$. Both association time and dissociation time

3 were $20 \mathrm{~s}$, and $1 \mathrm{M}$ arginine- $\mathrm{HCl}, \mathrm{pH} 4.4$ was used to regenerate the sensor chip surface. The running

4 buffer alone was used as a negative control, and $1 \mu \mathrm{M}$ TSP7 was used as a positive control. Solvent

5 correction was performed periodically. The binding response of each compound was normalized to

6 those of control samples and molecular weight using the Biacore 8K software.

8 ABA assay using SPR. For the secondary screen, we performed an ABA assay. EC12 was

9 immobilized on the Sensor Chip CM5 by amine coupling ( $\mathrm{pH} 4.5$ ). The immobilization level was

approximately 500 RU. Solution A was $2 \mu \mathrm{M} \mathrm{EC12,} \mathrm{and} 100 \mu \mathrm{M}$ compound identified in the primary

solution B was $120 \mathrm{~s}$, and that of the second injection of solution A was $120 \mathrm{~s}$

Selectivity analyses and mutation study. E-cadherin WT REC12, E-cadherin N140Y mutant, P-

cadherin WT REC12, and P-cadherin Y140N mutant were immobilized on chips via biotin-

streptavidin capture. All the constructs gave the binding response between 3000-4000 RU. Association

17 times were $15 \mathrm{~s}$ or $30 \mathrm{~s}$, and dissociation time was $20 \mathrm{~s}$. Hit 1 concentration ranged from $37.6 \mu \mathrm{M}$ to 
1 Solvent correction was performed at the beginning and the end of the concentration series.

3 Circular dichroism (CD) measurement. To confirm that point mutations of classical cadherin

4 constructs did not disrupt secondary structure, we performed CD measurements. CD spectra of 5 samples in $1 \mathrm{~mm}$ path-length quartz cells were measured at $20^{\circ} \mathrm{C}$ using a JASCO J-820

6 spectropolarimeter. Samples were prepared at $10 \mu \mathrm{M}$ in $10 \mathrm{mM}$ HEPES, $150 \mathrm{mM} \mathrm{NaCl}, 3 \mathrm{mM} \mathrm{CaCl}_{2}$,

$7 \mathrm{pH} 7.5$ buffer.

9 Crystallization of P-cadherin. For X-ray crystallography, conditions used previously for the C-

10 terminal-deleted REC12 and MEC12 (1-213) $)^{21}$ were used. Purified C-terminal-deleted REC12 (12.5

$11 \mathrm{mg} / \mathrm{mL}$ ) was crystallized in $100 \mathrm{mM}$ HEPES, pH 7.5, 28\% v/v PEG 400, $200 \mathrm{mM} \mathrm{CaCl} 2$. Purified C-

M Tris $\mathrm{pH} 8.5, \mathrm{w} / \mathrm{v} 25.5 \%$ PEG4000, 15\% v/v glycerol. The crystals were soaked with the crystallization solution containing 10\% DMSO and $10 \mathrm{mM}$ Hit 1 for several minutes. For the crystals of C-terminal-deleted REC12, crystal annealing ${ }^{43}$ was performed in order to decrease mosaicity.

17 Data collection and refinement. X-ray diffraction data sets were collected on the RIKEN Structural

18 Genomics Beamline II (BL26B2) at SPring- $8^{44}$. The diffraction data were processed with the KAMO 
1 programs ${ }^{45-47}$, and the structure was solved by molecular replacement, using the structure of P-

2 cadherin REC12 (PDB ID 4zmz) or MEC12 (PDB ID 4zmq) as a search model with phenix.phaser.

3 The resultant structures were iteratively refined using phenix.refine ${ }^{48}$ and manually rebuilt in $\operatorname{Coot}^{48}$.

4 Final refinement statistics are summarized in Table 1. Figures were prepared with UCSF Chimera ${ }^{49}$.

6 HDX-MS homodimer inhibition assay. To confirm the hypothesis from the crystallography that Hit

71 inhibits X dimerization, we performed HDX-MS and monitored the protein surface exposed to the

8 solvent with or without Hit 1 . We compared the extent to which the $\mathrm{X}$ dimer interface is exposed to

9 the solvent by preparing REC12 and MEC12 at $1.5 \mathrm{mg} / \mathrm{mL}$ protein in the $\mathrm{H}_{2} \mathrm{O}$-based $10 \mathrm{mM}$ HEPES,

exchange reaction was started by diluting $\mathrm{D}_{2} \mathrm{O}$-based buffer by 10 fold and was quenched by addition

of an equal volume of prechilled quenching buffer ( $8 \mathrm{M}$ urea, $1 \mathrm{M}$ Tris(2-carboxyethyl)phosphine

hydrochloride, $\mathrm{pH}$ 3.0) with the HDx-3 PAL (LEAP Technologies). The quenched protein samples

were subjected to online pepsin digestion and analyzed by LC-MS using UltiMate3000RSLCnano

(Thermo Fisher Scientific) connected to the Q Exactive HF-X mass spectrometer (Thermo Fisher

Scientific). Online pepsin digestion was performed using a Poroszyme Immobilized Pepsin Cartridge 
$115 \mathrm{~mm}$; Thermo Fisher Scientific) and Hypersil Gold $(1.0 \times 50 \mathrm{~mm}$; Thermo Fisher Scientific),

2 respectively. The mobile phases were $0.1 \%$ formic acid solution (A buffer) and $0.1 \%$ formic acid

3 containing $90 \%$ acetonitrile (B buffer). The deuterated peptides were eluted at a flow rate of $45 \mu \mathrm{L} / \mathrm{min}$

4 with a gradient of $10-90 \%$ of B buffer in 9 min. Mass spectrometer conditions were as follows: an

5 electrospray voltage of $3.8 \mathrm{kV}$, positive ion mode, sheath and auxiliary nitrogen flow rate at 20 and 2

6 arbitrary units, ion transfer tube temperature at $275{ }^{\circ} \mathrm{C}$, auxiliary gas heater temperature at $100{ }^{\circ} \mathrm{C}$,

7 and a mass range of $\mathrm{m} / \mathrm{z} 200-2,000$. Data-dependent acquisition was performed with normalized

8 collision energy of 27 arbitrary units. The MS and MS/MS spectra were subjected to a database search

9 analysis using the Proteome Discoverer 2.2 (Thermo Fisher Scientific) against an inhouse database

10 containing the amino acid sequence of the C-terminal-depleted REC12. The search results and MS

11 raw files were used for the analysis of the deuteration levels of the peptide fragments using the

HDExaminer software (Sierra Analytics).

14 SEC-MALS analyses. In order to measure the molecular size of each mutant, SEC-MALS analysis

was performed. Purified mutants were concentrated to $3.2 \mathrm{mg} / \mathrm{mL}$ in SEC buffer and loaded onto a

16 10/300 Superdex 200 column (Cytiva). Size measurement was performed using a Heleos 8+

17 instrument (Wyatt Technology) equipped with a triple MALS/refraction index (RI)/ultraviolet detector. 
1 Preparation of $\mathbf{C H O}$ cells expressing P-cadherin. To evaluate cell adhesion, we used the Flp-In-

2 CHO system (Life Technologies) to engineer $\mathrm{CHO}$ cells stably expressing full-length P-cadherin. A

3 single clone was obtained through the limiting dilution-culture method. The expression of P-cadherin

4 was monitored with an imaging cytometer (In Cell Analyzer 2000, Cytiva), because the DNA sequence

5 of monomeric GFP was fused at the C-terminal of the human P-cadherin constructs. CHO cells

6 expressing P-cadherin were cultured in Ham's 12 medium (Life Technologies) containing 10\% fetal

7 bovine serum (FBS), $1 \%$ penicillin-streptomycin, and $0.5 \mathrm{mg} / \mathrm{mL}$ hygromycin at $37{ }^{\circ} \mathrm{C}, 5 \% \mathrm{CO}_{2}$.

9 Cell aggregation assay. The cell aggregation assay was performed as reported previously ${ }^{33,34}$. We first

10 treated the $\mathrm{CHO}$ cells with $0.1 \%$ trypsin in HEPES-based magnesium-free buffer (HMF buffer, 10

$11 \mathrm{mM}$ HEPES, $137 \mathrm{mM} \mathrm{NaCl}, 5.4 \mathrm{mM} \mathrm{KCl}, 0.34 \mathrm{mM} \mathrm{Na}_{2} \mathrm{HPO}_{4}, 1 \mathrm{mM} \mathrm{CaCl}_{2}, 5.5 \mathrm{mM}$ glucose, $\mathrm{pH}$

12 7.4). These conditions result in digestion of protein molecules on the cell surface with the exception

13 of P-cadherin, which is resistant to trypsinization in the presence of $\mathrm{Ca}^{2+}$. The trypsinization was stopped by adding HMF buffer containing $10 \%$ FBS, and trypsin was removed by washes with HMF

buffer. After washing the cells with $\mathrm{Ca}^{2+}$-depleted HMF buffer (HCMF buffer), cells disaggregated.

$16500 \mu \mathrm{L}$ of cell solution containing $1 \times 10^{5}$ cells $/ \mathrm{mL}$ was placed in wells of a 24 well plate that had been

17 pre-treated with $1 \%(\mathrm{w} / \mathrm{v}) \mathrm{BSA}$. Addition of $1 \mathrm{mM} \mathrm{CaCl}_{2}$ in $2 \%$ DMSO initiated P-cadherin-mediated 
1 Hit 1 was added. Cells were incubated at $37^{\circ} \mathrm{C}, 80 \mathrm{rpm}$ for $30 \mathrm{~min}$, and images of the cells were taken

2 with an EVOS XL Core Imaging System (Life Technologies). To determine Hit 1 could disrupt the

3 cell aggregation, Hit 1 or EDTA was added $60 \mathrm{~min}$ after the addition of $\mathrm{CaCl}_{2}$. The images of the cells

4 were taken after 60 min.

6 Liposome aggregation assay. Lipids (DOPC: DOGs-NTA-Ni,9:1 molar ratio) were dissolved in

7 chloroform than dried. The lipids monolayer obtained was hydrated with $10 \mathrm{mM}$ HEPES, $150 \mathrm{mM}$

$8 \mathrm{NaCl}_{1} 3 \mathrm{mM} \mathrm{CaCl}_{2}$, pH 7.5 and subjected to 10 cycles of freeze and thaw. Liposomes were prepared

9 using a polycarbonate filter with $100 \mathrm{~nm}$ pore diameter in a Mini-Extruder apparatus (Avanti).

10 Based on a reported methodology ${ }^{50}$, liposomes with C-terminally His-tagged MEC12 were prepared

11 at a lipid to protein molar ratio of 50:1 in $10 \mathrm{mM}$ HEPES, $150 \mathrm{mM} \mathrm{NaCl}, 3 \mathrm{mM} \mathrm{CaCl}_{2}$, $\mathrm{pH}$ 7.5. After

$10 \mathrm{~min}$ at room temperature an excess amount of $\operatorname{EDTA}(8.3 \mathrm{mM})$ was added to deactivate the cadherin

spectrophotometer every $1 \mathrm{~s}$ for $1000 \mathrm{~s}$. Hit 1 or phenyl-Hit 1 diluted in DMSO was added to the

solution to a final DMSO concentration of $5 \%$ DMSO. The constant rate $K$ was calculated using

GraphPad Prism 8 software assuming exponential decay and one-phase association.

18 Cell area quantification. HCT116 and MCF7 cells were detached from the plate by trypsin and 
1 resuspended to the concentration of $1 \times 10^{5}$ cells $/ \mathrm{mL}$ in McCoy's 5 medium containing $10 \% \mathrm{FBS}$, and

$21 \%$ penicillin-streptomycin, $0.1 \%$ DMSO, and each concentration of Hit 1 . Aliquots of $100 \mu \mathrm{L}$ of the

3 suspended cells were plated into wells of a 96-well plate (Greiner) and incubated at $37{ }^{\circ} \mathrm{C}, 5 \% \mathrm{CO}_{2}$

4 for 2 days. After removing the medium, $100 \mu \mathrm{L}$ of $10 \mu \mathrm{M}$ Calcein AM (Invitrogen) in McCoy's 5

5 medium was added to each well and incubated at $37^{\circ} \mathrm{C}, 5 \% \mathrm{CO}_{2}$ for $30 \mathrm{~min}$. After washing with PBS

6 buffer, $100 \mu \mathrm{L}$ of PBS buffer was added, and images were taken using an In Cell Analyzer 2000

7 (Cytiva). The cell area was calculated using a method created with Developer Tool Box software. The

8 kernel size and intensity were adjusted for each cell to fully detect the area.

11 Acknowledgements

12 We thank Thermo Fisher Scientific for the technical support in HDX-MS experiments. This work

was supported by JSPS Grants-in-Aid for Scientific Research (16H02420 to K.T.), Platform Project

for Supporting Drug Discovery and Life Science Research (Basis for Supporting Innovative Drug

Discovery and Life Science Research (BINDS)) from Japan Agency for Medical Research and

Development (AMED) (JP19am0101094 to K.T.), and a Grant-in-Aid for JSPS fellows (A.S.). The

17 synchrotron radiation experiments were performed at BL26B2 of SPring-8 and were supported by 
1 Initiative supported by BINDS from AMED (JP19am0101086). This work was partly supported by

2 the World-leading Innovative Graduate Study Program for Life Science and Technology, The

3 University of Tokyo, as part of the WISE Program (Doctoral Program for World-leading Innovative

$4 \quad \&$ Smart Education), MEXT, Japan.

5

6 Data Availability statements

7 The authors declare that the data supporting the findings of this study are available within the paper

8 and its supplementary information files.

9

10 Author contributions

11 A.S., S.N., S.K., T.T., and K.T. designed experiments, analyzed and discussed the results, and approved

12 the manuscript. A.S., K.Y., S.I, G.U., performed crystallization experiments, and processed and

13 determined the crystal structure. A.S. and Y.S. synthesized Hit 1, Hit 1-carboxylic acid and phenyl-Hit

141 with input from S.S.. A.S. and S.N. wrote the manuscript with input from K.T.

\section{Competing interests}

17 The authors declare no competing financial interests. 


\section{$1 \quad$ Materials \& Correspondence}

2 Supplementary information containing additional figures, and tables and compound characterization

3 data is available as a separate file. Correspondence should be addressed to K.T. (tsumoto@bioeng.t.u-

$4 \quad$ tokyo.ac.jp) or S.N. (ngtoishi@ims.u-tokyo.ac.jp). 


\section{$1 \quad$ References}

2 1. Matthews, J. M. \& Sunde, M. Dimers, Oligomers, Everywhere. Adv. Exp. Med. Biol. 747, 1-18

2. Marsh, J. A. \& Teichmann, S. A. Structure, Dynamics, Assembly, and Evolution of Protein

Complexes. Annu. Rev. Biochem. 84, 551-575 (2015).

$63 . \quad$ Arkin, M. M. R. \& Wells, J. A. Small-molecule inhibitors of protein-protein interactions:

Progressing towards the dream. Nat. Rev. Drug Discov. 3, 301-317 (2004).

4. Smith, M. C. \& Gestwicki, J. E. Features of protein-protein interactions that translate into potent

inhibitors: topology, surface area and affinity. Expert Rev. Mol. Med. 14, 1-20 (2012).

6. Van Roy, F. Beyond E-cadherin: Roles of other cadherin superfamily members in cancer. Nat.

7. Idoux-Gillet, Y. et al. Slug/Pcad pathway controls epithelial cell dynamics in mammary gland 
19 Shimoyama, Y. \& Hirohasht, S. Expression of E- and P-Cadherin in Gastric Carcinomas1.

2

3 10. Siret, C. et al. Cadherin-1 and cadherin-3 cooperation determines the aggressiveness of pancreatic

Cancer Res. 51, 2185-2192 (1991). ductal adenocarcinoma. Br. J. Cancer 118, 546-557 (2018).

11. Ribeiro, A. S. \& Paredes, J. P-Cadherin Linking Breast Cancer Stem Cells and Invasion: A Promising Marker to Identify an "Intermediate/Metastable" EMT State. Front. Oncol. 4, 1-6 (2015).

12. Vieira, A. F. \& Paredes, J. P-cadherin and the journey to cancer metastasis. Mol. Cancer 14, 1-12 (2015).

13. Nakamura, T. et al. Overexpressed P-Cadherin/CDH3 Promotes Motility of Pancreatic Cancer Cells by Interacting with p120ctn and Activating Rho-Family GTPases. Cancer Res. 65, 30923099 (2017).

14. Kümper, S. \& Ridley, A. J. P120ctn and P-cadherin but not E-cadherin regulate cell motility and invasion of DU145 prostate cancer cells. PLoS One 5, (2010).

15. Patel, I. S., Madan, P., Getsios, S., Bertrand, M. A. \& MacCalman, C. D. Cadherin switching in ovarian cancer progression. Int. J. Cancer 106, 172-177 (2003).

16. Yu, W., Yang, L., Li, T. \& Zhang, Y. Cadherin Signaling in Cancer: Its Functions and Role as a Therapeutic Target. Front. Oncol. 9, (2019). 
1 17. Zhang, C. C. et al. PF-03732010: A fully human monoclonal antibody against P-cadherin with

antitumor and antimetastatic activity. Clin. Cancer Res. 16, 5177-5188 (2010).

18. Brasch, J., Harrison, O. J., Honig, B. \& Shapiro, L. Thinking outside the cell: How cadherins drive adhesion. Trends Cell Biol. 22, 299-310 (2012).

19. Shapiro, L. et al. Structural basis of cell-cell adhesion by cadherins. Nature. 2, 24-25 (1995).

20. Vendome, J. et al. Molecular design principles underlying $\beta$ strand swapping in the adhesive dimerization of cadherins. Nat. Struct. Mol. Biol. 18, 693-700 (2011).

21. Kudo, S., Caaveiro, J. M. M. \& Tsumoto, K. Adhesive Dimerization of Human P-Cadherin Catalyzed by a Chaperone-like Mechanism. Structure 24, 1523-1536 (2016).

22. Harrison, O. J. et al. Two-step adhesive binding by classical cadherins. Nat. Struct. Mol. Biol. 17, 348-358 (2010).

23. Burden-Gulley, S. M. et al. Novel peptide mimetic small molecules of the HAV motif in Ncadherin inhibit N-cadherin-mediated neurite outgrowth and cell adhesion. Peptides 30, 23802387 (2009).

24. Vedove, A. D. et al. Structure-Based Virtual Screening Allows the Identification of E ffi cient Modulators of E-Cadherin-Mediated Cell - Cell Adhesion. Int. J. Mol. Sci. 20, 3404-3420 (2019).

25. Doro, F. et al. Computational design of novel peptidomimetic inhibitors of cadherin homophilic 
2 26. Nardone, V. et al. Crystal Structure of Human E-Cadherin-EC1EC2 in Complex with a

Peptidomimetic Competitive Inhibitor of Cadherin Homophilic Interaction. J. Med. Chem. 59,

5089-5094 (2016).

27. Doherty, P., Williams, E., Blaschuk, O. W., Williams, G. \& Gour, B. J. A Novel Family of Cyclic Peptide Antagonists Suggests That N-cadherin Specificity Is Determined by Amino Acids That Flank the HAV Motif. J. Biol. Chem. 275, 4007-4012 (2002).

28. Paulina, A., Medina, X. \& Moroni, E. Chemical Antibody Mimics Inhibit Cadherin-Mediated Cell-Cell Adhesion: A Promising Strategy for Cancer Therapy. Angew. Chem. Int. Ed. 132, 28382844 (2020).

29. Senoo, A. et al. Inhibition of homophilic dimerization and disruption of cell adhesion by Pcadherin-specific small molecules from SPR-based assays. Chem. Commun. 54, (2018).

30. Tian, W., Chen, C., Lei, X., Zhao, J. \& Liang, J. CASTp 3.0: Computed atlas of surface topography of proteins. Nucleic Acids Res. 46, W363-W367 (2018).

31. Kozakov, D. et al. The FTMap family of web servers for determining and characterizing ligandbinding hot spots of proteins. Nat. Protoc. 10, 733-755 (2015).

32. Clark, A. M. \& Labute, P. 2D depiction of protein-ligand complexes. J. Chem. Inf. Model. 47, 1933-1944 (2007). 
$133 . \quad$ Urushihara, H., Ozaki, H. S. \& Takeichi, M. Immunological detection of cell surface components

related with aggregation of Chinese hamster and chick embryonic cells. Dev. Biol. 70, 206-216

(1979).

34. Nose, A. \& Takeichi, M. A novel cadherin cell adhesion molecule: Its expression patterns associated with implantation and organogenesis of mouse embryos. J. Cell Biol. 103, 2649-2658

(1986).

35. Shimoyama, Y. et al. Cadherin cell-adhesion molecules in human epithelial tissues and carcinomas. Cancer Res. 49, 2128-2133 (1989).

36. Kudo, S. et al. Disruption of cell adhesion by an antibody targeting the cell-adhesive intermediate (X-dimer) of human P-cadherin. Sci. Rep. 7, 39518-39532 (2017).

37. Jacob, M. S. \& Presti, D. E. Endogenous psychoactive tryptamines reconsidered: An anxiolytic role for dimethyltryptamine. Med. Hypotheses 64, 930-937 (2005).

38. Roager, H. M. \& Licht, T. R. Microbial tryptophan catabolites in health and disease. Nat. Commun. 9, 1-10 (2018).

39. Mawe, G. M. \& Hoffman, J. M. Serotonin signalling in the gut-functions, dysfunctions and therapeutic targets. Nat. Rev. Gastroenterol. Hepatol. 10, 473-486 (2013).

40. Brezun, J. M. \& Daszuta, A. Depletion in serotonin decreases neurogenesis in the dentate gyrus and the subventricular zone of adult rats. Neuroscience 89, 999-1002 (1999). 
1

41. Chang, H. Y. et al. Selective serotonin reuptake inhibitor, fluoxetine, impairs E-cadherin-

mediated cell adhesion and alters calcium homeostasis in pancreatic beta cells. Sci. Rep. 7, 1-13

(2017).

42. Kushnir-Sukhov, N. M. et al. 5-Hydroxytryptamine Induces Mast Cell Adhesion and Migration. J. Immunol. 177, 6422-6432 (2006).

43. Heras, B. \& Martin, J. L. Post-crystallization treatments for improving diffraction quality of protein crystals. Acta Crystallogr. Sect. D Biol. Crystallogr. 61, 1173-1180 (2005).

44. Ueno, G. et al. RIKEN structural genomics beamlines at the SPring-8; high throughput protein crystallography with automated beamline operation. J. Struct. Funct. Genomics 7, 15-22 (2006).

45. Yamashita, K., Hirata, K. \& Yamamoto, M. KAMO: towards automated data processing for microcrystals. Acta Crystallogr. Sect. D Struct. Biol. 74, 441-449 (2018).

46. Evans, P. R. An introduction to data reduction: Space-group determination, scaling and intensity statistics. Acta Crystallogr. Sect. D Biol. Crystallogr. 67, 282-292 (2011).

47. Kabsch, W. XDS. Acta Crystallogr. Sect. D Biol. Crystallogr. 66, 125-132 (2010).

48. MacCoy A., et al., Phaser crystallographic software. J. Appl. Crystallogr. 40, 658-674, 2007.

49. Pettersen, E. F. et al. UCSF Chimera--a visualization system for exploratory research and analysis. J. Comput. Chem. 25, 1605-12 (2004).

50. Sun, J., Vernier, G., Wigelsworth, D. J. \& Collier, R. J. Insertion of Anthrax Protective Antigen 
bioRxiv preprint doi: https://doi.org/10.1101/2020.08.30.274647; this version posted August 31, 2020. The copyright holder for this preprint (which was not certified by peer review) is the author/funder, who has granted bioRxiv a license to display the preprint in perpetuity. It is made available under aCC-BY-NC-ND 4.0 International license.

into Liposomal Membranes. 282, 1059-1065 (2007).

2

3 